\title{
O DISCURSO PEDAGÓGICO NA PERSPECTIVA DA ANÁLISE DO DISCURSO
}

\section{Arnaldo Nogaro*}

Resumo: O texto " $\mathrm{O}$ discurso pedagógico na perspectiva da análise de discurso" procura discutir questões importantes relativas à Análise do Discurso. Seu lugar, papel e como ela se constitui em uma área de conhecimento próprio e meritória de estudo.

$O$ autor procura num segundo momento, analisar o discurso pedagógico sob o olhar da Análise de Discurso, evidenciando como ele se constitui em um instrumento de reprodução, silenciamento e de manifestação de relações de poder. Há uma preocupação em explicitar a sala de aula como lugar da fala e ao mesmo tempo de silenciamento, ou seja, como lugar de coexistência de muitos discursos.

Palavras-chave: Análise do discurso, discurso pedagógico, escola.

\section{Para introduzir nossa fala}

Partindo da constatação que há inúmeras formações discursivas, de que existem várias possibilidades de significação e de que o sujeito não cria sentidos mas se apossa dos sentidos existentes já dados, propomo-nos discutir as questões que dizem

\footnotetext{
* Professor de Filosofia e Filosofia da Educação da URI- Campus de Erechim, Mestre em Filosofia, Doutorando em Educação - UFRGS.
} 
respeito à Análise de Discurso(AD) e sua intervenção ou contribuição no campo do Discurso Pedagógico (DP).

A hipótese ou a concepção em causa, de que são possíveis várias ou diferentes leituras e significações, formula-se dentro da concepção teórica de inspiração francesa, especialmente Pêcheux, e da brasileira Eni Orlandi, estudiosa e adepta desta corrente.

Dos inúmeros discursos existentes restringimos nosso ângulo de observação ao DP. Por que o DP? Pela relação próxima e intrínseca com o mesmo e por ver nessa análise a possibilidade de desmistificar e desconstruir algumas concepções arraigadas, "discurso pronto", a respeito das práticas existentes no espaço da escola e da sala de aula, materializadas na fala do professor, na obediência do aluno, no conteúdo do livro didático, na legislação que rege o ensino.

Tematizar o DP sob a ótica da teoria do discurso ou da AD constitui-se em um ângulo de observação diferenciado pela própria especificidade do campo de ação e atuação da $A D$, de como ela vê estas práticas. A AD se pretende uma teoria crítica que trata da determinação histórica dos processos de significação. Trabalha os processos e as condições de produção da linguagem. Ela não é uma teoria descritiva, nem explicativa. Ao colocar como fundamental o fato de que há uma relação necessária da linguagem com o contexto de sua produção a AD tem de articular-se sobre o campo das Ciências Sociais sem deixar de constituir sua unidade no interior da teoria linguiística. A AD problematiza a atribuição de sentido(s) procurando mostrar tanto a materialidade do sentido como os processos de constituição do sujeito, que instituem o funcionamento discursivo. Iluminados por esta perspectiva teórica é que vamos abordar as práticas discursivas da escola e da sala de aula que denominamos Discurso Pedagógico.

Num primeiro momento estabelecemos ou determinamos qual o campo de atuação da $\mathrm{AD}$, após, discutimos a noção de discurso e posteriormente tratamos do DP sob a perspectiva da reprodução, do silenciamento e dos jogos de poder presentes 


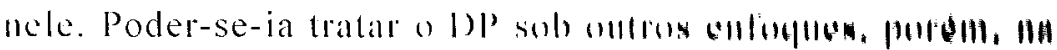

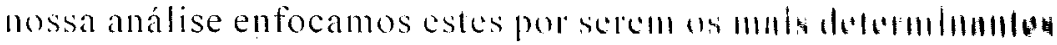

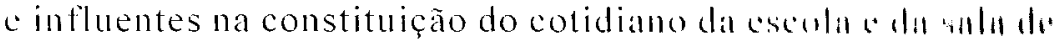
aula.

Utilizando-nos da AD como olhar clínico verifïcamos, ma última parte do texto, a possibilidade de outros sentidos, além daqueles postos existentes (como dominantes) na escola e na siala de aula.

\section{A noção de discurso e o lugar da AD}

A disciplina de AD é uma disciplina de entremeio. Ela se faz no espaço entre a Linguiistica e as Ciências Sociais. Ela se forma não como soma, mas como contradição entre as disciplinas. Ao levar em conta tanto a ordem própria da linguagem como o sujeito e a situação, não vem simplesmente juntar o que está necessariamente separado nessas diferentes ordens de conhecimentos; ela vai estabelecer sua prática na relação de contradição entre esses diferentes saberes. Ela vai tratar das questões que envolvem a produção do discurso. A AD não se constitui em uma hermenêutica na relação com o texto. Ela não é um método de interpretação, não atribui nenhum sentido ao texto. O que ela faz é problematizar a relação com o texto, procurando apenas explicitar os processos de significação que nele estão configurados, os mecanismos de produção de sentidos que estão funcionando.

Para a $\mathrm{AD}$, as condições de produção que regem cada situação de enunciação são responsáveis pelo(s) sentido(s) construído(s) para um discurso, uma vez que o inserem em um espaço histórico-social e inescapavelmente ideológico, em que se encontra também o sujeito produtor. Assim, cada texto, realização de um discurso, terá seu sentido determinado pelas condições de produção de sua escritura e/ou de cada leitura. $O$ sujeito é concebido como produtor de sentidos, mas sua inserção em um contexto histórico-social que permite determinadas 
formações discursivas, inscritas dentro de determinadas formações ideológicas, the confere o caráter de assujeitado a esse contexto. Dessa forma, a AD concebe os sentidos como sendo produzidos dentro de contextos histórico-sociais e determinados ideologicamente.

Dentro da AD nós vamos ver os discursos presentes no texto, na materialidade lingüística.

A Análise de Discurso produz realmente outra forma de conhecimento, com seu objeto próprio, que é o discurso. Este, por sua vez, se apresenta como o lugar específico em que podemos observar a relação entre linguagem e ideologia (ORLANDI,1994, p.53).

Por meio dela eu vou analisar os possíveis sentidos. Eu posso analisar e interpretar porque os discursos são abertos e podem ser interpretados. O discurso não é fechado em si mesmo e nem é do domínio exclusivo do locutor: aquilo que se diz significa em relação ao que não se diz, ao lugar social do qual se diz, para quem se diz, em relação a outros discursos.

A palavra "discurso" tem sido usada com vários sentidos. Isto graças à polissemia das palavras. O conceito de discurso é um conceito teórico e cuja delimitação é impossível de ser feita em termos práticos de análises pois não existe um discurso, mas um estado de um processo discursivo.

É preciso dizer que todo discurso nasce de outro discurso e reinvia a outro, por isso não se pode falar em um discurso mas em estado de um processo discursivo, e esse estado deve ser compreendido como resultado de processos discursivos sedimentados, institucionalizados.

O uso que Eni Orlandi faz do conceito de discurso é o da linguagem em interação, ou seja, aquele em que se considera a linguagem em relação às suas condições de produção, ou, dito de outra forma, é aquele em que se considera que a relação estabelecida pelos interlocutores, assim como o contexto, são constitutivos da significação do que se diz.

Falar em discurso é falar em condições de produção, e em relação a essas condições, gostaríamos de destacar que, como o exposto por Pêcheux (1979), são formações imaginárias, 
e nessas formações contam a relação de forças, a relaç̃o de sentido, a antecipação.

O discurso é uma das instâncias em que a materialidade ideológica se concretiza, isto é, um dos aspectos materiais da "existência material" das ideologias. Pode-se afirmar que o discurso é uma espécie pertencente ao gênero ideológico. Como a linguagem é o lugar por excelência do ideológico, analisar o discurso é descrever os "sistemas de dispersão" dos enunciados que o compõem através de suas "regras de formação".

A formação discursiva determina o que pode e o que deve ser dito a partir de uma certa região da formação social, a partir de um certo contexto sócio-histórico. Os fatos não narram a si mesmos, são narrados por um certo autor, de uma certa perspectiva, de uma certa maneira, para um certo público. Podemos dizer que o que define a formação discursiva é a sua relação com a formação ideológica.

É no discurso que se pode apreender a relação entre linguagem e ideologia, tendo a noção de sujeito como mediadora: não há discurso sem sujeito nem sujeito sem ideologia. O efeito ideológico elementaré o que institui o sujeito(sempre já-lá)(ORLANDI, 1994, p.54).

As formações discursivas são formações componentes das formações ideológicas e que determinam o que pode e o que deve ser dito a partir de uma posição dada em uma conjuntura dada.

São as formações discursivas que, em uma formação ideológica específica e levando em conta uma relação de classe, determinam 'o que pode e deve ser dito' a partir de uma posição dada em uma conjuntura dada (BRANDÃO,1994, p.38).

O jogo ideológico está na dissimulação dos efeitos de sentido sob a forma de informação, de um sentido único, e na ilusão discursiva dos sujeitos de serem a origem de seus próprios discursos. O discurso não é um conjunto de textos, é uma prá- 
tica. Para encontrar sua regularidade não se analisam seus produtos, mas os processos de sua produção. O discurso não é um reflexo da situação, não está mecanicamente determinado por ela.

O texto é o lugar onde vamos encontrar o discurso. No texto os discursos são amarrados, porém eles sempre são mais amplos que o texto. É por isso que nós dizemos que vamos usar o texto para encontrar o que não está no texto. O texto é o lugar onde eu vou procurar, vou fazer a AD. Esta vai analisar as posições representadas pelos sujeitos presentes no texto. Ele é o lugar onde nós vamos encontrar as diferentes posições de sujeitos. Do ponto de vista da AD o discurso é caracterizado enquanto interação. Dessa forma, posso dizer que texto e discurso se equivalem, entretanto em níveis conceptuais diferentes: discurso é conceito teórico e metodológico e texto é conceito analítico.

O discurso não é transmissão de informações mas como efeito de sentidos entre interlocutores, enquanto parte do funcionamento geral, tem compromisso com quem o produz, como é produzido. Ou, como define Pêcheux, "o discurso não é apenas transmissão de informação, mas efeito de sentidos entre locutores. E a AD é análise desses efeitos de sentido" (Pêcheux, apud Orlandi, 1986, p.115).

Os discursos têm ordem própria. Não se passa de uma coisa para outra como se o sentido fosse o mesmo.

Quando nós falamos fazemos opções de sentidos. Os sentidos não nascem em mim. Quando nascemos os sentidos já estão aí, nós os usamos. Se não existisse sentidos não teria sentido falar. Eles não estão colocados num lugar só, não é mudando a palavra que vamos mudar o sentido. É no modo de produção do discurso que se constrói a relação com o sentido. Isto significa dizer que o sujeito não é autônomo, não é dono absoluto do que diz. O sujeito quando produz linguagem também está reproduzido nela, acreditando ser a fonte exclusiva de seu discurso, quando na realidade retoma um sentido preexistente. O discurso é heterogêneo, o sujeito tem a ilusão 
da unidade do discurso, de que ele é dono, que se apropriou deste discurso. Ele tem a ilusão de que fechou o sentido. É necessário ver as condições de produção ou seja que situações sócio-históricas existiam para que o sentido fosse incorporado pelo texto. Todo texto supõe a relação dialógica, se constitui pela ação dos interlocutores, ou seja, o conceito de discurso se assenta sobre a relação dialógica na medida em que é constituído por interlocutores em determinadas condições de produção.

A cada "definição" de discurso que, por sua vez, deriva uma concepção de linguagem distinta, se propõe uma certa metodologia e uma espécie distinta de tipologia.

\section{O Discurso pedagógico como reprodução, silenciamento e relação de poder}

No que se refere à tipologia vamos encontrar vários tipos de discurso: pedagógico, religioso, histórico,... Em relação a estes discursos não há relações categóricas. Os discursos tendem para o autoritário, tendem para o lúdico. Nossa pretensão é analisar especificamente o discurso pedagógico enquanto perpassado e meio de reprodução, silenciamento e relação de poder.

O Discurso Pedagógico (DP), é um discurso circular, isto é, um dizer institucionalizado sobre as coisas, que se garante garantindo a instituição em que se origina e para a qual tende: a escola. Na medida em que a convenção, pela qual a escola atua, aparece como modelo, como obrigatória, tem o prestígio da legitimidade.

Quando incorporamos um discurso nós o modificamos, mas a tendência à reprodução é muito mais evidente. Usamos sentidos prontos por meio das palavras. Existe sempre um jogo entre o que volta e o que se traduz num sentido novo.

Os discursos institucionais são muito mais eficientes, nos produzem o tempo todo. A escola, como instituição, determina uma maneira de dizer. É a formação discursiva pedagógica. 
Ela incorpora uma maneira de dizer, torna isto seu discurso, oficializa-o. É preciso lembrar aqui em quem a escola se respalda: a classe dominante. Esta, legitimada, ainda que inconscientemente pela classe dominada, delega, num dado contexto histórico, a tarefa pedagógica de perpetuar seus valores, preencher suas necessidades e, consequientemente, punir toda rebeldia que impeça esta tarefa.

Assim, o discurso da escola, enquanto instituição, será o discurso do diretor, do professor, do aluno, que se torna sujeito deste discurso falando o que o professor quer ouvir, ficando quieto, calando-se,... O discurso predominante da instituição acaba por ser o discurso de todos os segmentos da escola indistintamente.

O DP, comumente, é visto como autoritário porque não leva em conta as condições de produção da leitura do aluno, fazendo com que o aluno real e o virtual concidam sem que se opere uma mudança nas condições de produção. No DP a reversibilidade tende a zero, estando o objeto do discurso oculto pelo dizer, havendo um agente exclusivo do discurso e a polissemia contida.

Pela posição do professor na instituição e pela apropriação do cientista feita por ele, dizer e saber se equivalem. "O discurso é o espaço em que saber e poder se articulam, pois quem fala, fala de algum lugar, a partir de um direito reconhecido institucionalmente" (BRAND ̃̃O, 1994,p.31).

E a voz do saber fala no professor. A fala do professor informa e, logo, tem interesse e utilidade. O que o professor diz se converte em conhecimento, o que autoriza o aluno, a partir de seu contato com o professor, no espaço escolar, na aquisição da metalinguagem, a dizer que sabe: a isso se chama escolarização. Enquanto ele for aluno "alguém" resolve por ele, ele ainda não sabe o que verdadeiramente the interessa, ... isso é inculcação.

O DP utiliza uma linguagem que dilui seu objeto ao mesmo tempo em que se cristaliza como metalinguagem: as definições são rigidas, há cortes polissêmicos, encadeamentos 
automatizados que levam a conclusões exclusivns. Nin ye lruta, então, da explicação dos fatos, mas de se determinar a per'spectiva de onde devem ser vistos e ditos. E nesta perspectiva o livro didático cumpre uma função exemplar. Ele nasce em condições de produção específicas, de um imaginário que, na maioria das vezes, pressupõe no professor o mito do estrangeiro. Isto é, as condições da realidade do autor e da produção são distintamente diferentes das do aluno. A "autoridade" do livro didático se constitui na medida em que é tido como depositário de um "saber" estável a ser decifrado, associado a uma maneira positiva de ver as coisas. Este poder que lhe é delegado está associado à institucionalização e alguém autorizado a manejálo: o professor.

Em todas as disciplinas, o livro didático representa em si um sentido já-lá, já-posto na aparência da unidade, do universal. Não há possibilidade de pluralidade de sentidos na relação do aluno com este conteúdo e as palavras devem coincidir com as coisas.

A formação discursiva do professor parece justificar não apenas o papel de detentor do 'saber' como' também a idéia de um dever a cumprir, ou seja, a responsabilidade que the é imputada pela transmissão de conhecimento ao aluno desprovido desse conteúdo (CORACINI, 1995, p.122).

Os discursos que os professores produzem não são tão inovadores. São mais conservadores que transformadores. E toda a sociedade reconhece como legítimo este discurso que a escola produz. Todos agimos dentro de um DP quando falamos na escola. Todos pensamos que o professor tem que ensinar e e o que ensinar. Se por um lado o professor é cobrado em termos de desempenho, como informador, animador, os alunos, inseridos numa formação ideológica dada e numa formação discursiva, legitimam inconscientemente a autoridade do mestre. A 
formação de informador imputada ao professor vem sempre acompanhada da idéia de facilitação dessa informação: afinal, é preciso tornar o objeto a ser ensinado acessível a quem não sabe.

O professor, então, dado o lugar que ocupa de autoridade institucionalmente reconhecida, é o único juiz do grau de explicitação pertinente, definindo, com o auxílio do material didático, que freqüentemente a escola e as editoras colocam à disposição, a progressão da matéria a ser aprendida até mesmo à revelia do interesse dos próprios alunos (CORACINI, 1995, p.43).

Assim o DP está instituído no sistema que o legitima por meio da organização do sistema: Ministério da Educação, Secretarias de Educação, Delegacias de Educação, Diretor,...

O controle total das aulas é sempre do professor, ele faz uso, ainda que de forma inconsciente, de estratégias próprias de um tipo de metodologia que conta com a prioritária "participação" dos alunos, dentre as quais a mais usada consiste em formular a pergunta de modo a obter a resposta desejada (seja oral ou escrita em forma de questionário). Os alunos não questionam as respostas que recebem do professor, esperam uma única resposta certa para cada tipo de questão e seguem à risca os passos para a realização da tarefa. É próprio do discurso autoritário fixar o ouvinte na posição de ouvinte e o locutor na posição de locutor. Dizer não é apenas informar, nem comunicar, nem inculcar, é também reconhecer pelo afrontamento ideológico.

Assim, o tipo autoritário é o que tende para a paráfrase (o mesmo) e em que se procura conter a reversibilidade (há um agente único: a reversibilidade tende a zero), em que a polissemia é contida (procura-se impor um sentido) e em que o objeto do discurso(seu referente) fica dominado pelo próprio dizer (o objeto praticamente desaparece) (ORLANDI, 1988, p.24).

Por que isto? No processo ensino-aprendizagem quem determina o que é correto ou não é o professor que, na maioria 
las vezes, coincide com o livro didático, que, por sua vez, scleciona o que deve ser aprendido. Porque o que o professor diz, por meio do livro didático, é o discurso legítimo, autorizado. () professor tem a "competencia" para dar ou autorizar esta resposta.

De fato pode-se dizer que é verdade que a autoridade do professor e do autor através de seu texto existem, considerando-se as condições de produção e circulação dos discursos na escola e o lugar ocupado pelo aluno na hierarquia escolar (CORACINI, 1995, p. 89-90).

Em nossas escolas e salas de aula os alunos continuam expostos a uma metodologia que os desconsidera total ou parcialmente enquanto seres pensantes e atuantes no seu processo de aprendizagem. Isto leva a nos questionarmos sobre as dificuldades de ensinar e aprender. Nós, professores, estamos excluídos desse dizer-ato-decisão quando se trata do discurso do poder que se pronuncia sobre a educação definindo seu conteúdo, sua forma, seu sentido, sua finalidade. Mas enquanto professores, não estamos excluídos do dizer-ato-decisão quando se trata do trabalho pedagógico. Caberia interrogar-nos: é possivel ser diferente?

Na sala de aula o sentido é produzido intersubjetivamente, entre professor e aluno. Mas qual é o espaço real para que o aluno produza significado ou intervenha na produção do significado? De modo geral, podemos dizer que o professor orienta inteiramente o raciocinio do aluno com perguntas padronizadas que não exigem reflexão. Por parte do aluno percebe-se uma inteira aceitação das regras convencionais do jogo de sala de aula, uma vez que ele acompanha as explicações do professor e, na maioria das vezes, as responde corretamente ou tenta fazê-lo.

De modo geral podemos afirmar que os "diálogos" que caracterizam as aulas são monopolizados pelo professor que comanda o raciocínio e o momento de intervenção do aluno, aceitando-a ou rejeitando-a conforme seus objetivos. Tal pro- 
cedimento visto como diálogo é discutível do ponto de vista da concepção filosófica de diálogo. Esta ação estaria muito mais para monólogo do que para diálogo. O diálogo da sala de aula tem por objetivo ensinar, desenvolver no aluno a capacidade de raciocínio, embora isso raramente aconteça. Isto tudo tem pouco a ver com o sentido de diálogo preconizado pelos Personalistas ou por Paulo Freire que vê no diálogo a possibilidade de ajuda e libertação do oprimido. O diálogo da sala de aula tradicional parece estar distante da maiêutica Socrática que pretendia desenvolver no discípulo a capacidade de raciocinar e elaborar soluções racionais para as questões colocadas.

As relações entre as pessoas, entre os indivíduos, são relações de poder, de maior ou menor exercício de poder. Toda relação social se dá sob certas condições histórico-sociais, e portanto ideológicas, que determinam o grau de aceitação dessas relações e se as mesmas podem ser modificadas ou não.

É porque o poder está enraizado e naturalizado em toda e qualquer relação intersubjetiva que é tão difícil dele se desprender. É porque se criam, nas relações humanas, regras de conduta e de uso da linguagem que a sala de aula se transforma numa verdadeira formação discursiva, abafando a multiplicidade de pontos de vista, de modos de vida e de desejos pessoais que, com certeza, subjazem a essa aparente homogeneidade, diferenças essas responsáveis pelas contradições e conflitos, capazes de provocarem verdadeiras mudanças internas e externas (CORACINI, 1995, p.64).

É preciso lembrar que a autoridade da escola e do professor se dá nas relações com a sociedade e, portanto, com os alunos. São essas relações que tecem toda a trama ideológica que atravessa o sujeito e constrói o discurso. São essas relações que se manifestam num dado momento histórico-social, as responsáveis diretas pelo imaginário discursivo que perpassa toda e qualquer interação social. Elas são espaço de fala, como também de silenciamento. O silêncio comumente é entendido como uma ausência de fala, um espaço vazio. Quando 
há silêncio, em uma cultura como a nossa, causa um certo desconforto, como se algo não estivesse certo. Mas na AD não estaremos falando deste silêncio mas de um silêncio carregado de significações. "Indo mais longe, a hipótese que partimos é a de que o silêncio é a própria condição de produção de sentidos"(Orlandi,1995, p.38), uma vez que antes de ser palavra todo sentido já foi silêncio, dito de outro modo, todo sentido posto em uma palavra já se dispôs antes em silêncio, na relação com o sujeito. Daí o silêncio significa por si mesmo, ou seja, o silêncio não fala, ele significa. Porque o silêncio enquanto espaço diferencial que permite à linguagem signifcar, é uma das instâncias em que se produz no movimento. Numa formação discursiva é possível dizer certas coisas, de uma certa forma, e não outras, de outra forma. O silêncio é a possibilidade do dizer vir a ser outro. "Essa é a razão pela qual entendemos a sala de aula como uma formação discursiva, o que não significa, de forma alguma a impossibilidade de mudança ou de conflitos" (Coracini, 1995, p.68).

Neste sentido, o silêncio não é um vazio que precisa ser preenchido, mas como Pêcheux nos diz "presença de não-ditos no interior do dito". Para um dizer há sempre muitos não ditos, é quase que uma correspondência vital.

A linguagem é sempre uma tomada de posição. No momento em que afirmo algo deixo de afirmar outra coisa. Quando falamos uma palavra não nos damos conta que estamos nos apropriando de um sentido que subjaz a esta palavra, que esta já pertence a um código lingüístico, foi criada para um determinado lugar. A opção por uma palavra e por um sentido determina o apagamento de outras palavras e outros sentidos. Este silenciamento se caracteriza por trabalhar sob uma forma de sentido. Ao dizer algo, silenciamos outros sentidos. Há sempre um jogo no qual todo movimento de censura corresponde a outro de resistência.

Quando o professor pede para o aluno ler um texto e o professor faz um comentário, transmite sua visão, diz o que ele viu no texto e que é assim que deve ser compreendido. As possí- 
veis compreensões ou sentidos do texto tornam-se a compreensão e o sentido. Permanece o sentido dominante e os demais sentidos subjazem, não aparecem. Ler significa, neste sentido, saber pronunciar as palavras como o professor e com o mesmo sentido. Esta visão colabora para o silenciamento do aluno no que diz respeito à produção do significado, como se apenas ao professor fosse permitido pensar e significar sobre alguma coisa, ou seja, orientar a leitura e a significação do texto. Assim o discurso do professor silencia o de seus alunos. Quanto mais o professor mantiver o "controle", lutar e argumentar para garantir seu espaço de significação, que acredita ser seu e somente seu, maior será o silêncio dos alunos Este "silêncio" dos alunos se dará por manifestações bem típicas das salas de aula de hoje: desinteresse, fingir que se está escutando, conversas paralelas, brincar com outras coisas... Por isso que é importante a reflexão que a $A D$ faz. Ela vai se preocupar com as condições de produção do discurso, com o que está presente no momento em que se materializa o discurso. Ela vai ver quem são os sujeitos produtores e quais as vozes apagadas, sujacentes, que coexistem no momento em que um discurso se sobressai ou é expresso. A isto denominamos prestar atenção às heterogeniedades discursivas, isto é, quais os discursos presentes, manifestos ou não.

Captar ou investigar quais os discursos silenciados ou não manifestos, muitas vezes nos dá um quadro muito mais real do que se passa na escola e na sala de aula do que ouvir e aceitar os discursos que estão manifestos ou são dominantes. E para isto precisamos aguçar nossa capacidade para ver e ir além das falas e práticas mais aparentes e penetrar nos acontecimentos mais reclusos que, muitas vezes, são o retrato fiel e a verdadeira alma de como a escola se conduz e se constitui.

\section{São possíveis outros discursos além dos existentes na escola e na sala de aula hoje?}

A AD pode contribuir mostrando que no DP deve-se ir além do evidente, ver coisas não ditas, considerar os pontos de 
vista que são plurais. Quebrar a lógica dos "donos dos discursos".

As práticas de leitura de nossas salas de aula são essencialmente enfatizadoras do linguiístico. Não se faz uma leitura sob a ótica ou da dimensão da AD. Os textos, comumente, não são abordados como documentos que revelam ideologias, crenças, valores. E muito menos que estes elementos vão construir a significação a partir do contexto sócio-históricoideológico de onde vieram. O texto na concepção e análise linguística se resume, "enfim, a um mosaico de palavras que, na leitura competente, recompõem o desenho predeterminado pelo autor e resgatam a coesão e coerência por ele atribuídas" (CORACINI, 1995, p.88).

Há a necessidade de mostrar que os sentidos não nascem nas pessoas, nem na autoridade. Os sentidos estão aí, nós os usamos. Se não existissem estes sentidos não teria sentido falar. A escola é o lugar da interpretação, nela há um controle da produção do discurso. Nela o sujeito é determinado e controlado.

É preciso mostrar que o discurso tem compromisso com quem o produz. Isto é, os sentidos são atravessados pela ideologia. Portanto é preciso ver os discursos presentes, materializados nos textos, nas práticas da escola, na materialidade linguiistica, uma vez que os sentidos não estão alocados em um lugar só.

A AD nos auxilia e nos mostra que os sentidos não são evidentes, que eles acontecem no social, no político, atravessados pela ideologia. E a ideologia, por sua vez, está materializada nos aparelhos de estado. Devemos ver que práticas representam as ideologias. E o discurso é uma das instâncias em que a materialidade ideológica se concretiza, isto é, um dos aspectos materiais da "existência material" das ideologias. O discurso tem compromisso com quem o produz, como é produzido, daí haver uma tendência pela manutenção do sentido e da reprodução do discurso. Isto porque cada sujeito tem um sentido de evidência e acín que aquilo que pensa só tem aquele sentido. 
De acordo com Pêcheux, o sujeito do discurso se caracteriza por dois esquecimentos ou duas ilusões que poderiam ser assim sistematizadas; a) O sujeito tem a ilusão de que é uno, é a origem do sentido; b) O sujeito tem a ilusão de que o que diz tem apenas um significado, isto é, todo interlocutor captará suas intenções e suas mensagens (CORACINI, 1995, p.27).

É preciso explicitar para o aluno que as condições de produção da leitura de $u$ m texto dentro da sala de aula vai produzir sentidos diferentes da leitura do mesmo texto em uma situação não-didática. Deve-se deixar claro para o aluno que existe uma injunção ideológica que se revela nas posições hierarquizadas de sala de aula e, conseqüentemente, na relação professor-aluno. É preciso deixar claro para o aluno que

[...] lidar com textos é, enfim, discutir a ilusão da consciência plena que nos faz acreditar na única leitura, no bom sentido, na verdade que justamente essa consciência nos fez alcançar, ainda que ilusoriamente(CORACINI, 1995, p.91).

$O$ autor sempre coloca de maneira predominante aquela posição que ele assume. Assim o escritor vai escrever de algum lugar e o leitor vai ler de algum lugar. É a posição que cada um assume ao dizer ou ao interpretar um sentido. Precisamos nos dar conta que na sociedade e na escola coexistem muitos discursos e não só um que normalmente aparece como predominante. A AD serve para mostrar que a construção do conhecimento não se dá somente pelo discurso predominante. A AD tem a preocupação de ver a que rede de sentido as palavras pertencem.

Quando o processo ensino-aprendizagem ocorre a partir de material didático publicado, o aluno já começa a perceber que há um sentido "pronto", predeterminado e que deve ser interpretado, deve ser buscado. Não há qualquer embate com o texto para ver quais os demais sentidos possiveis. O texto é tomado como um conjunto rígido de palavras que vão se com- 
pondo para revelar o sentido do texto na sua transparência e lixidez, muito dirigida, em busca de adoção de uma atitude mais crítica em relação à confortável posição de encontrar um saher "organizado", com tudo em seus devidos lugares, como manda o senso comum.

Para Pêcheux, desmistificar a ilusão do livro didático enquanto depositário de um saber imutável, hierarquizado, pode levar alunos e professores e refletirem sobre uma tradição herdada de atividade didática.

É preciso ainda considerar que o saber transmitido em aula, geralmente descompassado com relação às pesquisas teóricas ou aos modelos propostos pelas metodologia de ensino, passou, é evidente, pela leitura do professor que, por sua vez, em muitos casos, aprendeu através de outros professores... Este movimento que parece não ter fim e que denuncia a pluralidade de vozes que constituem todo sujeito e todo conhecimento, ao lado da imagem que o professor faz de seu grupo de alunos, de suas experiências prévias e de sua formação profissional é, sem dúvida alguma, o grande responsável pela transformação do saber, que pode chegar aos limites do que se pode chamar banalização e, assim, não ensinar nada ou quase nada como parecem evidenciar resultados de muitas de nossas práticas pedagógicas nas escolas.

Construir uma prática pedagógica diferente da que está posta aí começa por determinar e mapear quais os discursos que sustentam tais práticas. Passar as práticas pelo crivo da crítica e apontar os dircursos dominantes, muitas vezes oculto pelas ideologias, é o passo inicial para revitalizar o espaço da escola e da sala de aula. A AD ganha força e espaço como lugar que possibilita esta postura diferente e este campo de ação diferenciado na construção de outras práticas pedagógicas. Práticas estas que visam emancipar e trazer a tona discursos que até então permaneceram silenciados, mas que se manifestos contribuiriam para novas práticas pedagógicas, tão necessárias no cotidiano da escola. 


\section{Referências}

ALTHUSSER, L. Ideologia e aparelhos ideológicos de Estado. Lisboa: Presença, 1974.

BRANDÃ $\mathrm{O}, \mathrm{H}$. Introdução à análise do discurso. Campinas: UNICAMP, 1994.

CORACINI, Maria José. (org). O jogo discursivo na sala de leitura: língua materna e língua estrangeira. Maria José Coracini (org). Campinas:Pontes, 1995.

ORLANDI, E. A linguagem e seu funcionamento. Campinas: Ed. Ponte, 1996. Discurso \& leitura. São Paulo: Cortez, 1988.

Discurso, imaginário social e conhecimento. Brasília, Em aberto, ano 14, n.61, jan/mar. 1994.

2, n.1, 1986.

A análise do discurso: algumas considerações. DELTA, vol.

PÊCHEUX, M. Semântica e discurso: uma crítica à afirmação do óbvio. Campinas/SP: Ed. da UNICAMP, 1995. 